\title{
Increasing Brain Power beyond Imagination-Aligning Neuroscience and Social Psychology to Aid Prevention
}

\author{
Eddie John Paul Fisher \\ Faculty of Social Sciences, Universidad de Oriente, Santiago de Cuba, Cuba \\ Yorkys Santana Gonzalez \\ Faculty of Social Sciences, Universidad de Oriente, Santiago de Cuba, Cuba
}

Eddie Fisher (Corresponding author)

8 Kendal, Swindon, Wiltshire, SN5 8HW, United Kingdom

Tel: 44-179-349-0423Ｅ-mail: eddie.fisher9@btinternet.com

Received: May 29, 2017 Accepted: July 5, 2017

doi:10.5296/ber.v7i2.11301ＵRL: https://doi.org/10.5296/ber.v7i2.11301

\begin{abstract}
Brain science and cognitive psychology are in high demand amongst professions such as social psychology, education and science. Advancing the capabilities of the human brain in terms of power to benefit society and improve people's lives has become a topic of increasing value and interest to social psychologists. This research, limited to a literature review and a number of face to face interviews with psychology students to add some contemporary perspectives, investigated how increases in brain power could be achieved and what the potential benefits could be to social psychologists. Results suggest that short term brain power increases can be achieved through the application of low risk neurocognitive approaches such as brain training and by consuming natural brain foods and nutritional brain drugs. Infra-red laser stimulation of certain parts of the human brain not only increases cognitive brain power permanently but has the potential to reduce or eliminate brain diseases such as dementia and autism. Caution should be exercised to maintain the humanity element of what makes people human prior to engaging in long term brain power increase activities.
\end{abstract}

Keywords: Brain Power, Cognitive Abilities, Infra-red transcranial laser stimulation, Social Psychology, Neuroscience 


\section{Introduction}

\subsection{Introduction}

It appears that brain development and associated solutions to reduce or eliminate brain diseases has become a topic of interest recently. Brain power specialist consultants all over the world can help people to improve their brain power in areas such as working memory, thinking ability, improving sleep and controlling anxiety. Neuroscientists have been able to advance technology in areas such as infra-red laser stimulation and brain food drugs to reduce the likelihood of brain diseases developing and/or to eliminate these. The exploration of these new avenues is not finite and more work needs to be done to perfect the expected outcomes and reduce associated risks such as retaining long-term memory at the expense of losing short-term memory. Ageing causes changes to the brain size, vasculature, and cognition (Peters, 2006). The brain shrinks with increasing age and there are associated changes at all levels from molecules to morphology. Incidence of stroke, white matter lesions and dementia rise with age. The same applies to the level of memory impairment and there are changes in levels of neurotransmitters and hormones. According to the United States Alzheimer Association's 2012 report, for example, it is estimated, based on current trends, that between $11 \mathrm{~m}$ and $16 \mathrm{~m}$ people in the United States will suffer from this disease by the year 2050 . Reports issued by the National Institute for Neurological Disorders and Stroke (NINDS, 2006) and Centres for Disease Control (2012) confirm that the number of people who suffer from mental disorders, is on the increase, too. This will put more pressure on social psychologists to respond in appropriate ways to help people improve their social lives.

Recent research (TheAtlantic,2017) suggests that people increasingly value material goods over relationships. Neuroscientists have been arguing for some time that this goes against human nature. Lieberman (2013) purports that human beings have a basic need to belong to a group and to form relationships. Lieberman suggests that the brain is the centre of the social self and that social belonging motivates an increasingly impressive array of our thoughts, actions and feelings. It appears that there are new opportunities for the brain to get ready for what comes next in social terms. 'To the brain, social pain feels a lot like physical pain-a broken heart can feel like a broken leg' (Lieberman, 2013). Social connections are as important to human survival and flourishing as the need for food, safety and shelter.

This current research has adopted Allport's definition of what social psychology is (1985) as 'an attempt to understand and explain how the thoughts, feelings and behaviours of individuals are influenced by the actual, imagined or implied presence of others' (1985:3). Crisp and Turner (2010) suggest that social psychology tries to understand the social behaviour of individuals in terms of both the internal characteristics of a person (such as personality and mental processes) and the external influences (such as the effect of the social environment). They report that research on social psychology has continued to rapidly expand and diversify over the last 60 years.

This research covers a number of areas within social psychology such as self-awareness, attribution (attributing causality to actions we observe), attitudes (psychological characteristics that define who people are) and social influence (how people's thoughts, 
feelings and behaviours change in the presence of others).

Many brain power consulting companies such as Mind Power Consulting, LLC, Brain Power Consulting, Mentoring Metamorphosis and Visible Dynamics (OMQ Consulting) offer to help individuals and organisations, for example, to improve their Communications, Work Place Productivity and Personal Excellence. Their approaches include changing old behaviours and developing new skills and identifying the specific skills, habits and attitudes that should be focused on to improve performance at work. Hypnosis Mentoring/Hypnosis is considered to create a trance-like-state (Mentoring Metamorphosis, 2017) in which people experience flow-like focus and concentration (Fisher and Santana Gonzalez, 2016). Hypnosis appears to exercise better control over undesired behaviours, for example. This is usually conducted with the help of a therapist using verbal repetition and mental images, for example. If the brain were a computer, it could perform 38 thousand trillion operations per second (Quora, 2017).

The world's most powerful computer can only manage to achieve $0.002 \%$ of that Typical brain processes include learning (at all levels), keeping body and brain alive, co-ordinate body based on sensory input (unconscious) and self-awareness. The creation of even a single thought takes some serious computing power. The holding of information appears to be relatively easy whereas the thing that holds the information to know that it is holding it, is another level of brain complexity that is not yet clearly understood. If the processing that creates consciousness in itself could be enhanced, imagine what value this could add to, for example, improving the social lives of people (one of the primary roles of social psychology). Could brain memory devices be plugged into the brain to achieve this, a kind of central repository? What security and safety issues does this bring with it (Section 4)? How could Social Psychology benefit from increases in brain power? There appears to be an overlap between neural science and social psychology in areas such as attitude, behaviour and self-consciousness.

The aim of this research is twofold: 1 To investigate how, and to what extent, brain power could be increased 2 To investigate the potential impacts this could have on social psychology. Next a literature review is presented together with the Main Research Questions. This is followed by the Methodology, Results, Discussion and Conclusion sections.

\subsection{Literature Review}

Social (cognitive) neuroscience is concerned with the comprehension of the human brain's processes that enable human beings to understand each other, understand themselves and to find their way around what is generally known as the social world human beings exist within. According to Lieberman (2007), social (cognitive) neuroscience investigates social phenomena and processes using cognitive neuroscience research tools such as neuroimaging (production of the structure or activity of the human brain) and neuropsychology (study of the physical human brain and behaviour). The distinction between automatic versus controlled processes has long been important to social psychological theory. Following some research, Lieberman concludes that social (cognitive) neuroscience can both draw on and contribute to social psychological theory. Hengky (2015) and Ochsner and Lieberman (2001) consider that 
social (cognitive) neuroscience is engaged to understand phenomena in terms of their interactions at:

1. The social level-concerned with the motivational and social factors

2. The cognitive level-concerned with information-processing mechanisms

3. The neural level-concerned with the brain mechanisms that represent cognitive-level processes

A social (cognitive) neuroscience approach involves conducting studies and constructing theories. The ability to communicate socially is essential for human beings to be able to express themselves and interact well in social situations through appropriate use of language. This includes the sharing of information, training, interacting with others, resolving conflicts and raising awareness.

Hewstone et al. (2008) argue that there is a difference between social psychology and other related disciplines such as personality psychology and sociology. Social psychologists typically focus their attention on manipulating important aspects of the social context (of research) to assess the impact these changes have on the thoughts, feelings and behaviour of the target audience. Personality psychologists are less interested in the impact of the social context on behaviour. They focus their attention on asking why some participants (in research) are influenced by the erroneous judgements of the majority while others remain unaffected. The area of interest here is 'the personality traits that are responsible for the fact that different individuals act differently in what is essentially the same social situation' (page 8). In contrast, social psychologists study the impact of the social situation on individual behaviour. Hewstone et al. point out that these distinctions need to be viewed in context as one of the central concepts of social psychology, namely social attitudes. This is defined by many social psychologists such as Eagley and Chaiken (1993) as a tendency (individual disposition) to evaluate an attitude object positively or negatively. The ethical consequences in these areas, if brain power were increased through intervention, will be discussed in Section 4.

According to Shining Universe Energy Books (2015), the brain is the human body's most complex organ. Body movements, behaviour, the interpretation of the five senses and people's intelligence is controlled by the brain. It appears that scientists know more about the human nowadays due to advances in research that relates to behavioural and neurological science. The brain is the human body's command centre. It controls everything human beings say, do and think about. A constantly conditioned and healthy brain can help overcome negative emotions and stress. It is possible to force the brain to change or adapt (known as neuroplasticity). Applying some appropriate stimulation, existing connections can be altered, new neural pathways can be formed and the brain can be engaged to react and adapt in constantly changing ways. The brain has different parts that work together and it is essential to understand how. Table 1 is a summary of the configuration of the human brain. It should be noted that there are lesser dopamine receptors (implicated in many neurological processes such as motivation, cognition and memory) in the brains of highly intelligent people (thalamus dopamine receptors). This means that more thoughts are allowed to pass though. 
The problem-solving and potential for creativity a person may have could be substantially improved. It should be considered what the consequences could be if the same were applied to, for example, highly intelligent people and people who are in need to improve their social lives.

Table 1. Basics of the Brain (Shining Universe Energy Books, 2015)

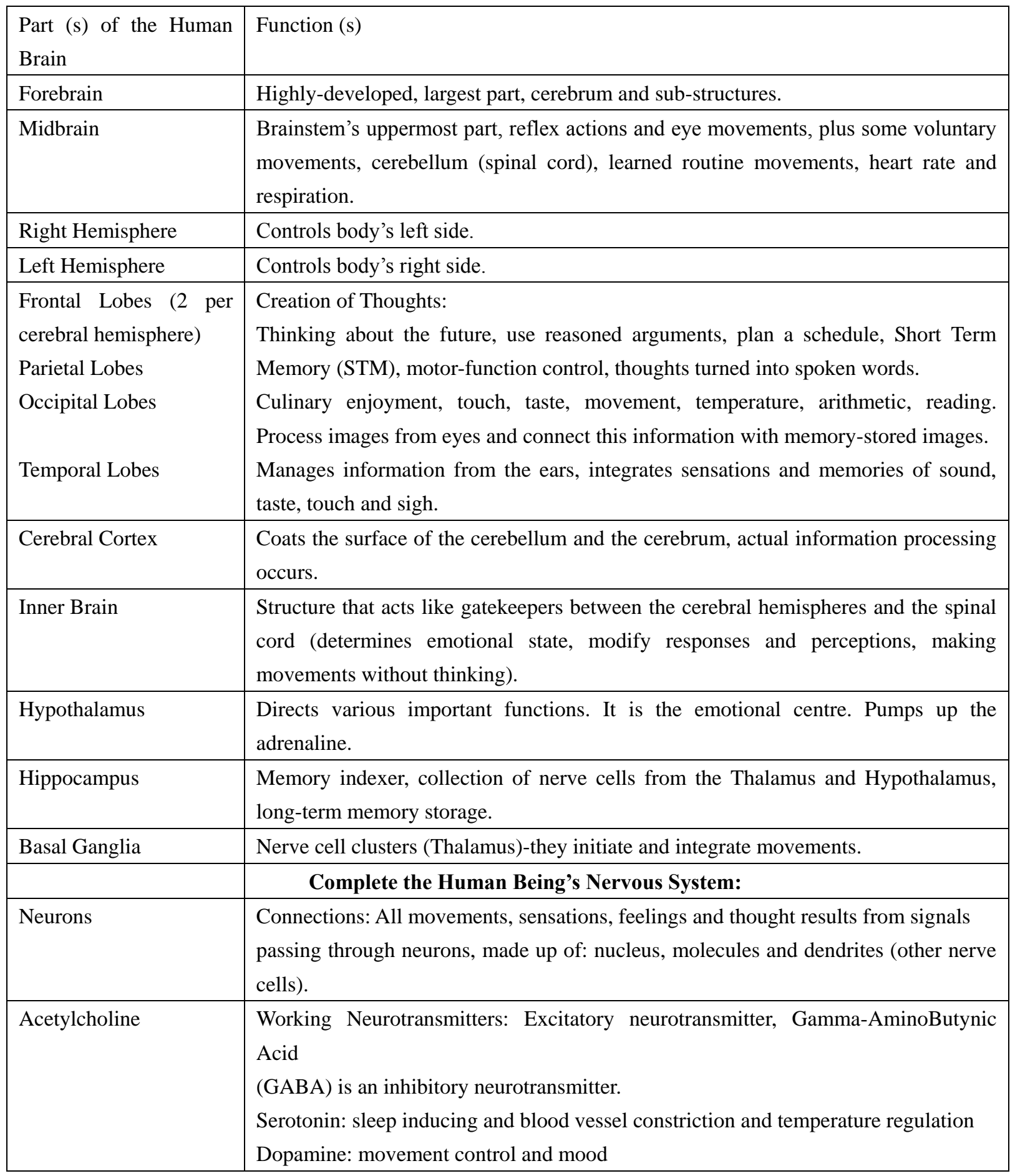

Neuroscience, also known as neural science, is the study of how the nervous system develops, its structure, and what it does. Neuroscientists focus on the brain and its impact on behaviour 
and cognitive functions. The prefrontal cortex area of the brain is thought to have a role in a wide range of complex social-cognitive behaviours, including making inferences about what other people are thinking and processing information about the self (Crisp and Turner, 2010). According to some research conducted by Mitchell et al. (2005) concluded that the prefrontal cortex is specifically used when trying to understand the attributes that other people possess but not for making more general judgements about others. The prefrontal cortex of research participants showed greater activation when participants saw themselves to be similar to the individual about whom they were making inferences. It appears that they were able to better predict the behaviour of the individual on the basis of how they themselves would feel in the same situation.

Johnson and de Haan (2015) discuss that cognitive neuroscience studies in adults have revealed a network of structures involved in the perception and processing of social stimuli, including interpreting the thoughts and intentions of other humans. Considerable debate remains about the developmental origins of this brain network. It appears that, at the basic level, the visual social brain is the perception of faces. There are two extreme views. The first one claims that there is an innate cortical module for face processing, known as the maturational view. The other one purports the expertise for faces is acquired in the same way as visual expertise for non-social stimuli, known as skill learning view. One of the major characteristics of the brain is its social nature. Adult people have areas of the brain specialised for processing and integrating sensory information about the appearance, behaviour and intentions of other humans. Mentalistic understanding of others' behaviour, the so-called theory of mind, has been associated with various neural structures, including the Amygdala (beyond the perception of faces, eyes and the actions of others, the developing child needs to develop neural and cognitive mechanisms for understanding the behaviour of others in terms of their intentions, goals and desires. The Amygdala is the integrative centre for emotions, emotional behaviour and motivation. It plays a primary role in the processing of memory, decision-making and emotional reactions.

Faumillan (2015) considers that the processes in the brain are all linked to one another. When one process fails to perform its job, another will fail to do its job as well and the cycle continues. Senses are also dependent on what the brain 'transmits'. There appears to be a strong relationship between the brain and the senses. Faumillan suggests that it is essential to understand how memory, concentration and cognition work before even considering how these could be improved. It is of equal importance to understand how people's actions affect these areas of the human brain. For example, behaviour and attitude could negatively affect concentration (Fisher and Santana Gonzalez, 2016). People's lifestyles and how they look after themselves, for example, keeping physically/mentally fit and eating appropriate food, has a major influence and impact on the mental well-being of people.

Markley (2015) suggests that the brain can be compared to a computer: data is received, categorised and then stored in the relevant file. Pathways similar to the root directories in a computer not only process what we have learned but also aid recovery of this at a later stage. The mind appears to create every person's own reality around it. It interprets, for example, the colour blue and other experiences people have. This means that people who look at the 
same colour, will experience it in a different way. In addition, the brain's subconscious mind plays an important role. The more negativity is fed into the subconscious mind, the worse people's lives will be. The converse is equally true. Human beings can influence external factors by simply letting the subconscious mind do its job. Feeding the subconscious mind with positive 'attitudes', influences, for example, what people can and will achieve. According to Markley, scientists only recently discovered that daydreaming is actually important when it comes to the subconscious mind's processing and communicating of information with the rational mind. The human mind switches off completely during sleep. It is only during this time that the subconscious mind is totally in control over the rational mind. The subconscious has the necessary quality time to engage, for example, in things that people have been thinking about during the day but could not make any sense of.

Eagleman (2015) argues that the main business of the brain is to predict. To do this well, people need to continuously learn about the world from their personal experiences. Eagleman argues that decision-making is of paramount importance to human beings. It is about who human beings are, what they do and how they perceive the world around them. Without this ability, human beings would not be able to navigate the now or plan their future lives. Although every individual has a single identity, people are not of a single mind: individuals are a collection of many competing drives. Gaining further insights into how choices battle it out in the brain, humans can learn how to make better decisions for themselves and the society they live in. For the brain to function normally, apart from food, oxygen and water, the brain needs one other but perhaps the most important ingredient-it needs other people. Normal brain function depends on networking with other people. The individual's neurons require the neurons of other people to prosper and stay alive. People's social skills are deeply rooted in people's neural circuitry. Human survival depends on quick assessments of who is a friend and who is an enemy. Human beings navigate the world by judging other people's intentions, according to Eagleman. Human beings are hard-wired to be social creatures. People cannot help but simulate others and connect with others, care about others. In this context, social pain (such as that emanating from exclusion) activates the same brain regions as physical pain. The human drive to bond with others is known as eusociality or good-sociality. It is what holds together tribes, groups and nations, irrespective of affinity. The eusociality of people is the driving force/catalyst behind making the world perceive/live in a better place through stronger alliances and confederations.

Mlodinow (2012) reports that some of the unconscious aspects of the human mind were actively speculated by Carl Jung and Sigmund Freud over the past century. The early approaches by these and other pioneers provided only fuzzy and indirect knowledge about the human unconscious mind. Today, sophisticated new technologies have contributed immensely to the understanding of the so-called subliminal world. A new science exists known as the science of the unconscious. The so-called science of the mind, for example, has been developed to allow scientists to collect data from the brain to reconstruct an image of what people are looking at (fMRI or functional Magnetic Resonance Imaging). It appears that the interplay between the human brain's conscious and sub-conscious mind is complex. Human beings benefit from a conscious and a sub-conscious mind. People's feelings, 
judgements and behaviours are constantly shifting between these two. It is possible, with the help of modern instruments, to watch different structures and sub-structures in the brain generate feelings and emotions. This helps human beings to understand what causes physical change in stress-related regions, for example. (Suomi, 1997; Spinelli et al., 2009).

Dunning et al. (2004) conducted some research to study how and when people's perception of reality is shaped by their preferences. A horse/seal dual image flashed onto a computer screen for a second and participants in the research would either see the image as a horse (farm animal) or a seal (sea creature). Depending on their choice, participants had the option to drink either a nice orange juice (if farm animal was selected) or a vile-tasting health smoothie (if a sea creature was selected). The beverage they were to drink was communicated by the computer and this was dependent on their choice of image. Half the participants were told 'farm animal equals orange juice' and 'sea creature equals smoothie'. The other half were told the opposite. The participants' motivations biased their perceptions: a) those who hoped to see a farm animal, $67 \%$ reported seeing a horse b) those hoping to see a sea creature, $73 \%$ identified a seal. Every day human being life experiences are far more complex. For example, talent at running a business or military unit and the ability to get on well with others, are all complicated qualities. The effect an increase in brain power could have on the subconscious mind will be discussed in Section 4.

Thaler and Sunstein (2008) claim that humans can influence decisions, for example, about health, wealth and happiness by playing to the brain's unconscious networks. A small enforced change in people's environment can change behaviour and decision making for the better, without people being aware of it. For example, placing fruit at eye level in a supermarket pushes people towards making healthier fruit choices. Pasting a picture of a housefly in urinals at Airports makes men aim better. This kind of soft paternalism of gently guiding the human subconscious brain has a far more powerful influence on people's decision making than outright enforcement. The positive consequence this could have on social psychology will be discussed in Section 4.

Neisser (2014) suggests that the human mind can be seen as a complex type of computer engaged in a set of processes that could be specified and modelled. To understand human nature, it is a necessary condition that human beings understand perception, attention, memory, thinking, problem solving and language. Neisser's focus has been on areas such as mnemonic, auditory, visual, stimulus equivalence and linguistics (Fig.1). Neisser does not directly claim that, for example, a $10 \%$ or $20 \%$ increase in brain power could or would affect all cognitive areas of the brain such as auditory and visual. It is implied that it does. 'Visual cognition, then, deals with the processes by which a perceived, remembered and thought-about world is brought into being from as unpromising a beginning as the retinal patterns. Similarly, auditory cognition is concerned with transformation of the fluctuating pressure-pattern at the ear into the sounds and the speech and music that we hear' (page 4). Neisser purports that human behaviour and consciousness depend entirely on the activity of the brain, interacting with other physical systems. Just like a computer, the brain has limitations such as imposing limitations on the organisation of mental events. This depends on the input/output routines of the rain. Briefly exposed stimuli are reported to the brain but 


\section{Macrothink}

Business and Economic Research

ISSN 2162-4860

2017, Vol. 7, No. 2

they depend on the code that the subject has available. If a verbal representation is long and disorganised, people tend to forget some of it very quickly. A permanent stimulation, it appears, could improve people's brain power significantly, leading potentially to endless new ways of working, for example, and developing improved prosocial behaviours. Pattern recognition, or stimulus equivalence, is ubiquitous within psychology. Applying tachistoscopic (displaying an image for a specific amount of time) experiments, Neisser argues that whenever a stimulus evolves a single response consistently, it is possible to say that it is being 'recognised'. It is not so important where the inputs to the process of pattern recognition come from. Far more relevant and significant are their orientation. For example, turning a square by 45 degrees produces a diamond instead; turning a book page by 90 degrees makes it difficult to read its content.

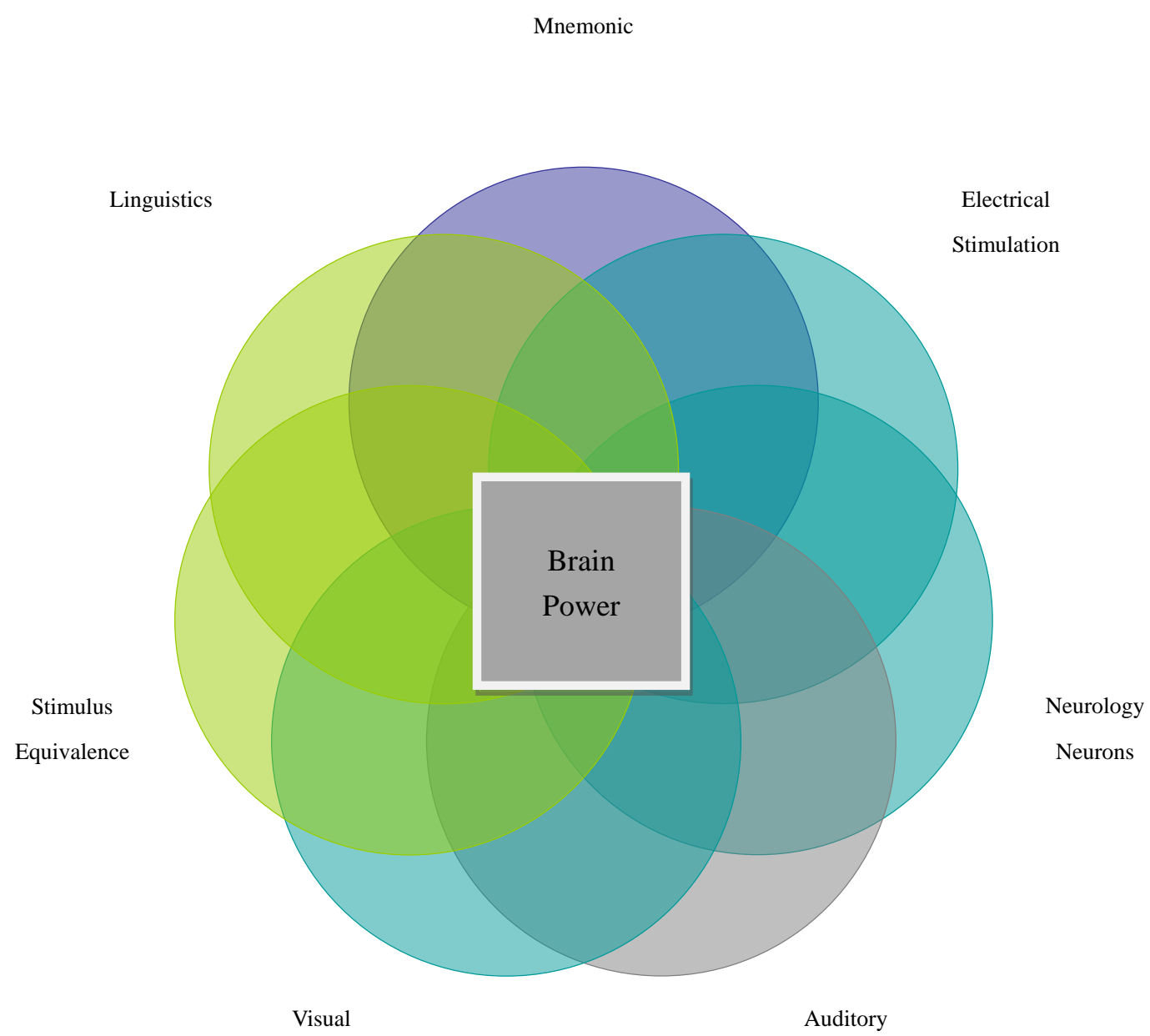

Figure 1. Cognitive Brain Power Model (Fisher and Santana Gonzalez, based on Neisser (2014) 
According to Lindenberger (2016), a developed so-called 'memo work method', improved cognitive abilities. 101 young adults aged 20-31 years and 103 persons aged 65-80 years trained for 1 hour every 2-3 days, for a total of 100 sessions. The study was designed to test how effective brain training is at improving general cognitive abilities, and to see if age improves these abilities. These researchers wanted to ascertain if progress in brain training could be transferred to everyday life. The results were that significant improvements could be observed in cognition, especially for working memory. Human beings require working memory to plan, understand complex topics, solve problems and learn new things. All participants, regardless of their age, showed improvements in working memory capacity following the training. It appears that the training positively altered and strengthened the neuronal connections between the two frontal lobes of the brain. Barratt and Gonzalez-Lima (2013) conducted the first transcranial controlled laser stimulation on cognitive and emotional functions in humans. The test focused on whether low-level laser stimulation produces beneficial effects on frontal cortex measure of attention, memory and mood. The collected, analysed and evaluated data implied that transcranial stimulation could be used as a non-invasive and efficacious approach to increase brain functions such as those related to cognitive and emotional dimensions. It appears that this approach could lead, for example, to the development of non-invasive, performance-enhancing interventions in healthy humans. This research's goal was to experiment with low-level light therapy (LLLT) to enhance frontal cortex cognitive and emotional functions. LLLT produces a wide range of biological effects including the enhancement of energy production, gene expression and the prevention of cell death. One element of this research was to test whether LLLT benefits extend to cognitive processes involving attention, vigilance and short-term memory. The outcome of the tests suggest that memory retrieval latency and correct match-to-sample trials improved significantly in the treated group. Whilst the delivered energy doses appear to be too low to cause damage, they appear to be sufficiently high enough to modulate neuronal functions (Sommer et al., 2001; Wong-Riley et al., 2005 and Rojas and Gonzales-Lima, 2011).

According to Simons (2013), the brain allows human beings to focus their attention on one thing only. The brain, therefore, has to prioritise what is really important. What is not important, is either ignored or filtered out. It appears that the brain suffers from 'change blindness' or an inability to keep track of changes. Due to limited attention, the brain computes a far smaller subset of changes than would normally be expected. The one thing that the brain focuses on, receives full attention which explains why high levels of detail are experienced. The brain is hardwired with incalculable shortcuts to essentialise the world. It works on a total power of 12 watts only. The two distinct parts of the brain responsible for this prioritisation of what really counts are known as the prefrontal cortex and the parietal lobe. They both act as a kind of switching station to allow shifts of attention. Attention amplifies the process of perception. The consequence of this for human beings is that they miss a lot of the world at any given moment in time. The brain does not expect, for example, background details to change. This explains why human beings are not consciously aware of many changes. Unexpected stimuli such as a phone ringing are dealt with by the sensory cortices that form part of the human brain. 
Strayer (2013) suggests that true multitasking does not exist. Human beings simply switch from one task to another. Attention and focus capability are still limited to a single task. The brain fills in so-called cognitive blind spots to create a seamless version of reality (in-attentional blindness). Automatic efforts of the brain can be turned off through hypnosis by switching off automatic signals that arise through areas of the brain: attention manipulation. Attention can be pushed to extreme levels so that brain functions can be modulated. This includes actions, feelings, and thoughts. For example, under hypnosis, the number 4 can be temporarily erased from the brain. When counting the number of figure of both hands, the number 4 is omitted. This temporary shutting off of the number 4 can be corrected again by reintroducing the number 4 under hypnosis. Through regular application of hypnosis and meditation, the brain can be re-wired.

Wikipedia (2017) reports details of a new film called 'Ghost in the Shell' which was released on 31 March 2017 in the United Kingdom. The film plays in the near future. The plot follows a woman who has her brain placed in a cyborg (human mind in a cybernetic frame) to become the perfect soldier. The vast majority of humans are augmented with cybernetics, enhancing various traits such as vision, strength and intelligence. It is claimed that she still feels, thinks and intuits just like a normal human being. A mechanical body, or shell, has been developed that accommodates the human brain. In essence, a combination of brain and artificial body has been created. The integration of the brain is in lieu of an Artificial Intelligence (AI). This concept is referred to as cyber-enhancement. Mental interfaces with the Internet and other networks have been created and enabled. The human brain's superiority over an AI brain is maintained. The film raises some questions about human rights, freedom of choice, lack of compatibility between the brain and the shell, visibility of thoughts, individuality/identity, reality and lack of new learning within the brain by not using the five human senses. This will be discussed in Section 4 together with concerns regarding human hacking.

\subsection{Main Research Questions/Hypotheses}

The main research questions for this research are:

1. How could brain power be increased and how could this be achieved?

2. Which parts of the brain would be best suited to achieve brain power increases?

3. What are the potential benefits to Social Psychology, particularly in the area of Attribution?

\section{Research Methodology}

\subsection{Method}

The researchers applied a constructivist interpretivist research approach within a phenomenological research paradigm. This qualitative research approach was considered most appropriate as the researchers wanted to get close to the subject matter under investigation within what they consider to be a socially constructed world. The primary focus was on finding evidence of what was already known about the subject matter under investigation and then enhance this knowledge through the integration of contemporary views 
from the face to face interviews. Table 2 is a summary of the questions asked during the face to face meetings with the research participants. All answers were recorded in writing or electronically where possible. Students provided their full approval. 20 undergraduate third year psychology students from the Universidad de Oriente in Santiago de Cuba, Cuba were interviewed over a three months' period in the third quarter of 2016. Of these 11 were female $(55 \%)$ and 9 were male (45\%). Their average age was 22 years. All students had extensive knowledge and practical experience of psychology including a detailed understanding of the structure and functions of the human brain. They provided valuable insights and provocative thoughts for further research.

Table 2. Research Questionnaire for the Face to Face Interviews

\begin{tabular}{|l|}
\hline 1. How can brain power be increased? Explain your answers. \\
\hline 2. What could be achieved by increasing brain power? Give examples. \\
\hline 3. Which parts of the brain would be best suited to achieve brain power increases? Why is this so? \\
\hline 4. What are the potential effects on short term and long-term memory? \\
\hline
\end{tabular}

\subsection{Data Collection and Interpretation}

The researchers considered two methods to collect relevant research data to answer the main research questions from Section 1.3: a review of the literature (Section 1.2) and face to face interviews (Section 3), within the context of a phenomenological research paradigm and an associated constructivist interpretivist research approach. The outcome of each research method such as literature review and face to face interviews increased the contributions made to answer the research questions from Section 1.3. The findings from each of the research methods such as literature review and face to face interviews were based on an evidential analysis and interpretation of all collected research data. This was enriched by the contemporary view contributions from the interviewees and allowed for a balanced view to be presented. All interviews were conducted in a consistent and methodical manner. The researchers probed further from time to time when interviewees were not forthcoming with sufficient supportive evidence. The result was an increased level of data reliability and validity.

\section{Results}

\subsection{Face to Face Interviews}

\section{How can brain power be increased? Explain your answers.}

'Just like physical exercises, conducting intellectual exercises enhances the operation of the human brain. Meditation (emotional intelligence and cognitive training) and didactic games can also improve our brain power'(Aymara; Leidis; Marisol). 'Focusing on exercises that improve both the short and long-term memories could, over time, improve the coding and decoding of the information that is fed to the brain, thus allowing for higher quality of information being presented to our brain' (Milena; Dayana; Bruno; Alberto).

'To carry our regular physical and cognitive training exercises to avoid cognitive deterioration. For example, attend to several tasks simultaneously and play challenging 
computer games' (Robert; Ernan). 'Ensure that the brain learns and continues to learn something new every day. Keep the challenges going so that the connections between our brain cells are strengthened and new connections develop that lead to an increase in our brain cells, and as such, our brain power' (Yenia).

What could be achieved by increasing brain power? Give examples. 'With an increase in our brain power, we should see and experience higher levels of attention, improved memory (both short and long term) and increased levels of perception. We could elevate our mental, and perhaps even physical, capacities. This would be of benefit to Social Psychology as it would help us to develop more prosocial attitudes and behaviours. This could have a big impact on social influence as this affects, positively, how our thoughts, feelings and behaviours change in the presence of other people'. (Leidis; Alina). 'We could increase our brain power to exceed the current 5-10\% maximum we appear to be using. It would enable us to tackle more complex tasks, become far more creative than we could ever have imagined and we could achieve things that we could only dream of in the past such as true simultaneous multi-tasking and faster and more accurate computation of mathematical equations without the need to revert to using calculators. We could also improve the social contexts that form parts of our existence and reduce our aggressive behaviour' (Jose). 'We could increase our operational capacities and perhaps achieve more with far less effort by co-ordinating activities much better and reducing wasting time by finding new ways of doing things differently. We could learn much faster by retaining what we have learned much better and we should also be able to associate things learned from the past to a better advantage as far as the future is concerned. An increase in brain power would allow our brains to see the 'connections' between pieces of information much better and clearer and use this to our advantage. It would be possible to improve intergroup relations as part of social psychology by improving individuals' understanding and thus alleviation of the forces that compel groups to come into conflict with each other.' (Maria; Pedro (2); Nataly).

Which parts of the brain would be best suited to achieve brain power increases? Why is this so? 'I suggest that some of the areas such as occipital, temporal and parietal lobes would benefit from an increase in power as they are responsible, for example, image processing, STM, arithmetic and reading abilities and the integration of sensations and memories' (Lesvia; Carlos; Raiza; Jose). 'We should leave the brain as it is and not interfere. The brain looks after itself, constantly striving to fix any damaged areas and creating new neural connections.'(Leidis; Mariso;Katia). 'The prefrontal cortex would be my area of concentration. Transcranial stimulation such as infra-red laser would have positive effects on our cognitive and emotional well-being/abilities.'(Bruno). 'I think that the frontal lobes would provide the area of the greatest benefits. They are involved in things such as body movements, solving problems, our judgements and our social behaviours.' (Alberto;Pedro;Robert). 'The parietal and occipital lobes. This would allow for increases in the capacity of our memory and attention' (Ernan; Raiza;Yenia).

What are the potential effects on short term and long-term memory? 'It would give human beings unlimited access to experienced and stored information that the brain collected through the five senses. We would never forget what we have already known but also our 
short-term memory would never let us down again. It would be like being connected to a HDD drive with instant access to unlimited storage irrespective of when that information was captured. It would be like having a permanent photographic memory.' (Aymara;Leidis;Alina). 'It would help human beings to improve the coding and decoding of information in line with the current working practices of our brains. It would help us become better at eliminating ambiguity so we can avoid holding fixed and oversimplified images of people and things and misjudging people we do not know well. Our interpretations of people and things would improve significantly. We could also bring theory and practice much closer together' (Milena;Dayana;Bruno). 'Human beings would be able to develop higher levels of sensory perceptions, and as such, improve our hearing, vision, sense of taste and sense of smell.' (Pedro;Ernan). Table 3 is a summary of the potential practical and theoretical application of the collateral knowledge generated by this research.

Table 3. Application and Ranking of the examined Cognitive Abilities

\begin{tabular}{|c|c|c|}
\hline $\begin{array}{l}\text { Cognitive } \\
\text { Abilities }\end{array}$ & Potential Applications & Ranking \\
\hline Perception & $\begin{array}{l}\text { Increased recognition ability to interpret sensory stimuli } \\
\text { such as hearing and seeing. }\end{array}$ & $\begin{array}{l}\text { Considered important by the } \\
\text { literature review }\end{array}$ \\
\hline Attention & $\begin{array}{l}\text { Increased concentration and focus levels and being able to } \\
\text { manage competing demands simultaneously (true } \\
\text { multi-tasking). }\end{array}$ & $\begin{array}{l}\text { Identified by all parties as } \\
\text { being important * }\end{array}$ \\
\hline Memory & Improved STM and LTM. & $\begin{array}{l}\text { Identified by all parties as } \\
\text { being important * }\end{array}$ \\
\hline Motor Skills & $\begin{array}{l}\text { Increased control over muscles and body and being able to } \\
\text { exercise greater control over manipulating bodies. }\end{array}$ & $\begin{array}{l}\text { Considered important by the } \\
\text { literature review }\end{array}$ \\
\hline Language & $\begin{array}{l}\text { Increased ability to translate sounds and verbal capacities } \\
\text { such as bilingual competence. }\end{array}$ & $\begin{array}{l}\text { Identified by all parties as } \\
\text { being important * }\end{array}$ \\
\hline $\begin{array}{l}\text { Visual and Spatial } \\
\text { Processing }\end{array}$ & $\begin{array}{l}\text { Increased ability to interpret and act on visual and spatial } \\
\text { stimuli }\end{array}$ & $\begin{array}{l}\text { Identified by all parties as } \\
\text { being important } *\end{array}$ \\
\hline Social Skills & $\begin{array}{l}\text { Increased ability to develop pro-social behaviours and } \\
\text { plan/execute goals to improve social lives. }\end{array}$ & $\begin{array}{l}\text { Considered important by the } \\
\text { Face to Face Interviews }\end{array}$ \\
\hline
\end{tabular}

*=Literature Review and Face to Face Interviews

\section{Discussion}

Successful people share an ability to engage their brains to improve their potential and to aid achieving their set targets. It appears that those who have developed critical abilities such as motivation and resilience are more likely to achieve their goals, both at work and in their private lives. The brain mechanisms of attention and control can be reshaped depending on how people use these. So-called non-invasive brain stimulation can enhance cognitive functions by long-term manipulation. This enables the brain to form new neural connections throughout life. Cognitive training interventions (sometimes referred to as brain training) can improve general mental capacity. This must be viewed in the context of limiting factors one of which is that every human being reacts differently to training. This also affects whether 
any potential cognitive improvements will be long or short term. If invasive permanent brain stimulations were conducted across areas of the brain such as the prefrontal, orbitofrontal, association, motor and somatosensory cortices, the impact on people's lives would be significant. It would seriously impact the formation of attitudes, behaviours, perceptions and working memory to name but a few.

It appears that the phenomenon of increasing brain power has not been truly recognised until recently. The Science of the Brain has become a fast-moving subject of immense interest. Recent research in the area of how the brain functions and works has provided a better understanding how brain power could be increased and which parts of the brain would benefit the most. Associated cognitive neuroscience studies in adults has established that a network exists in the brain that is engaged with the perception and processing of social stimuli. This includes how other people feel and what their intentions are. Johnson and Haan confirmed through the results of their research that the brain has a social nature. There appears to be a knowledge gap, for example, between permanent increases in brain power and what the potential positive benefits of increases in brain power could be, for example, for social psychology, and as such, society as a whole.

Neuroscience and Social Psychology have been co-evolving for some time but have not been working together closely enough to push the boundaries of what could be done to apply current knowledge of how the human brain works, for the benefit of people and society. Knowledge about the human brain will increase immensely in the near future. What are mysteries today will become new realities in future. Current theories and frameworks will be updated and new ones will be developed. It will necessary to continue with experiments in order to generate new knowledge and to test theory and practice. This is of paramount importance.

For example, applying infra-red laser stimulation to parts of the human brain could affect what is generally described as 'free will' as, it appears, human beings may no longer be able to make choices as these will be made for them. Neuroscience does not appear to have acceptable experiment outcomes to keep the concept of free will or choice active. Another view is that in reality nothing is predictable due to the immensely complex nature of the human brain. These appear to be forces beyond human control, at least for the time being.

Potential increases in brain power, although being short term, are not dependent on physical interventions such as infra-red laser treatments. For example, so-called brain nutritional drugs such as Prevagen, help to boost memory, concentration and mental drive. Many of these drugs contain only natural ingredients. It appears that these drugs will enhance brain power temporarily and people who wish to improve their brain power will need to continue to take these drugs regularly. Similar results can be expected from some food that is also known as brain/inspiring brain food. Regular consumption of berries, walnuts, whole grains, eggs and nuts/seeds, for example, is known to cater for brain development, cognitive functions and slowing down the ageing process. In addition, hypno-mentoring and behavioural transformation approaches appear to be focusing on the social dynamics of the human brain. As opposed to the other two, these approaches provide long term brain power increases. 
There are now opportunities to change the brain forever. It is no longer necessary to accept the brain as a given fixed entity. Technological advancements, new knowledge and desires to change the status quo of the human brain provide the necessary capabilities to achieve this. It is possible to imagine that people will become capable of conducting many tasks simultaneously and not be restricted by previous brain power limitations such as being able to focus on a single task only. Completing two different tasks on two personal computers at the same time could become the expected norm. People would be able to speed read in record time without any loss of relevant and important information. They would able to retain all knowledge for as long as they wish and discard any knowledge/memory that is no longer relevant to them.

Human intervention to increase permanent brain power through infrared stimulation, for example, does not come without risks, negative consequences and ethical issues. Enhancing the power of the conscious mind could have adverse effects on the sub-conscious mind, such that the power of the sub-conscious mind could eliminate the power of the conscious mind altogether. There is not a sufficient understanding what would or could happen if message impulses at the subliminal level were used to stimulate the brain through the subconscious.

There are human rights concerns, too. Increasing brain power way beyond people's imaginations and comprehensions may carry human rights issues. Humanity, for example, is what makes the human race. It is made up of the qualities that make human beings human. This includes the ability to show empathy, compassion, care and concern for fellow human beings. Substantial increases in brain power could affect these adversely. Similarly, the freedom of choice or free will may also be affected as human beings may no longer be able to choose freely between different possible courses of action.

It will be necessary to consider the consequences any increases in brain power could have on how different parts of the brain interact. Something called emergence happens when individual parts of a complex structure interact. The slightest imbalance could have a serious impact on how the whole structure (brain) functions. It is a necessary condition to understand first how individual parts of the human brain interact before engaging in substantial brain power increase activities.

\section{Conclusions}

This primarily knowledge-based research focused on identifying how brain power could be increased and what the potential benefits could be to individuals, society and social psychologists who would benefit by being able to improve the social lives of people significantly.

Cognitive strengths can be improved with relative ease by changing, for example, the way people think, feel and behave. Neuro-cognitive approaches to improve the functioning of the human brain are available now. These are non-invasive, carry very low risks to those who engage in this form of brain training and lead to noticeable long-term improvements in areas such as self-awareness, attention and emotional stability. Other benefits to the individual are improved memory and an ability to recover more quickly from difficulties. 
Nutritional brain drugs appear to increase brain power temporarily. More research needs to be conducted to find safe and acceptable solutions to achieve long-term brain power improvements without the need for regular top-ups. It appears that brain foods make a major contribution to keep the brain well nourished, and as such, provide a means to increase brain power at the pure nutritional level.

Infra-red laser stimulation takes potential increases in brain power to higher levels than the previously discussed approaches. Employing technological interventions carry higher risks not only at the individual level but at societal level as a whole. In the absence of all knowledge about the brain and its interactions between all constituent parts, it is necessary to exercise extreme caution when conducting brain power stimulations. It is imperative to conduct new experiments to gain new insights and a better understanding how the whole brain works and then assess what the positive benefits and potential negative consequences are for mankind.

Although it is no longer necessary to accept the status quo of the human life cycle, the creation of 'ghosts in a shell', for example, should not be the prime focus of neuroscientists. Placing human brains into so-called cyborg shells should not be priority for neuroscientists' attention. It is of much greater value to conduct future research to investigate the potential application of Nano-technologies, for example, to increase brain power exponentially at atomic, molecular and supramolecular levels. Further investigations should be conducted, for example, to assess the viability of replacing primary brain cell batteries through the application of novel electrode contact geometrics. A utilitarian approach that concentrates on what is of the greatest benefit to the human race should be applied.

The relationship between neuroscientists and social psychologists need to be strengthened for the benefit of human beings and society as a whole. There needs to be more focus on prevention rather than cure. Human beings are within reach of eliminating current brain diseases such as Alzheimer's (dementia, disorder of the mental processes), Creutzfeldt-Jakob (rapid worsening of brain damage over time) and Autism (lifelong developmental disability). Improving people's social lives must be top priority but it needs to be in an ethical and appropriate way that is focused solely on the well-being of people.

Another area that requires further investigation is brain stimulation in young people including babies. Although the number of brain cells in young people is the same as in adults, it is how these cells are connected that is of particular importance. Many connections are lost due to a lack of use. Early in life intervention or stimulation could potentially lead to retaining these connections and thus increase brain power. Any reservations or ethical issues connected with this approach need be considered first before engaging in such life-changing activities. More research is necessary to investigate this still relatively unknown territory of the human brain to gain further insights into the potential effects, for example, infra-red laser stimulation could have on the brain of babies or young people. Benefits should far outweigh any associated risks.

The brain can perhaps be compared to the engine of a car: both have capacity and tolerance levels for tuning to increase power but when increases in power exceed certain levels, 
longevity and reliability levels decrease exponentially. Associated risks of failure or malfunction increase accordingly. The consequence to the human brain is far more serious than that to a non-living entity such as a car.

This research was limited to a general Literature Review of mostly contemporary publications and the insights of a group of third-year psychology students from the Universidad de Oriente in Santiago de Cuba. Interviews with neuroscientists and practising brain surgeons would have produced valuable practical insights and views. In addition, interviews with students from other countries would have enhanced the richness of the research data and provided more universally applicable research data.

It is confirmed that the research questions from Section 1.3 have been answered.

\section{Acknowledgements}

The corresponding author wishes to thank the Universidad de Oriente in Santiago de Cuba for providing access to interview students from the Faculty of Psychology outside of formal teaching hours to assist with the completion of this research.

\section{References}

Allport, G. W. (1985). The historical background of social psychology. In G. Lindzey \& E. Aronson (Eds.), Handbook of social psychology, 1, 1-46.

Barratt, D. W., \& Gonzalez-Lima, F. (2013). Transcranial Infrared Laser Stimulation Produces Beneficial Cognitive and Emotional Effects in Humans. Neuroscience, 230, 13-23. https://doi.org/10.1016/j.neuroscience.2012.11.016

Companion Publication (2012). BrainFacts- A Primer on the Brain and Nervous System. [Online] Available: http://www.brainfacts.org (March 17, 2017)

Crisp, R. J., \& Turner, R. N. (2010). Essential Social Psychology. Second Edition, Sage Publications Ltd., https://doi.org/10.1111/j.1529-1006.2004.00018.x

Dunning, D. et al. (2004). Flawed Self-Assessment: Implications for Health, Education, and the Workplace, Psychological Science in the Public Interest, 5(3), 69-106.

https://doi.org/10.1111/j.1529-1006.2004.00018.x

Eagleman, D. (2015). The Brain-The Story of You. Canongate Books Ltd., Edinburgh, UK

Eagley, A. H., \& Chaiken, S. (1993). The psychology of attitudes. Fort Worth, TX: Harcourt Brace Jovanovich

Faumillan, F. (2015). Brain Power-The Ultimate Guide, Content Arcade Publishing

Hewstone, M., Stroebe, W., \& Jonas, K. (2008). Introduction to Social Psychology-A European Perspective. Fourth Edition, Blackwell Publishing Ltd.

https://www.neuronation.com/landingpage/memo-work-a-en/nn-opt/O?lang=en\&1p-c=tabool

Hengky, S. H. (2015). Co-Management: Social communications'gaps of Coastal Tourism in Seribu Islands. Environmental Management and Sustainable Development, 4(2), 204-216. 
https://doi.org/10.5296/emsd.v4i2.8524

Johnson, M. H., \& de Haan, M. (2015). Developmental Cognitive Neuroscience. Fourth Edition, Wiley Blackwell

Lieberman, M. D. (2013). Social-Why Our Brains Are Wired to Connect. First Edition, Crown Publishers, New York

Lieberman, M. D. (2007). Social Cognitive Neuroscience: A Review of Core Processes. Annual Review of Psychology, 58, 259-89.

https://doi.org/10.1146/annurev.psych.58.110405.085654

Lindenberger, U. (2016). Max Planck Institute for Human Development. Berlin, Germany

Mentoring Metamorphosis. (2017). Personal Development. [Online] Available: http://www.mentoringmetamorphosis (March 17, 2017)

Mitchell, J. P., Banaji, M. R., \& Macrae, C. N. (2005). General and specific contributions of the medial prefrontal cortex to knowledge about mental states. NeuroImage, 28, 757-762. https://doi.org/10.1016/j.neuroimage.2005.03.011

Mlodinow, L. (2012). Subliminal: How Your Unconscious Mind Rules Your Behaviour. Pantheon

Neisser, U. (2014). Cognitive Psychology. Psychology Press Classic Editions, New York and London

Ochsner, K. N., \& Lieberman, M. D. (2001). The emergence of social cognitive neuroscience. American Psychologist, 56(9), 717-34. https://doi.org/10.1037/0003-066X.56.9.717

Peters, R. (2006). Ageing and the Brain. Postgraduate Medical Journal, 82(964), 84-88. https://doi.org/10.1136/pgmj.2005.036665

Rojas, J. C., \& Gonzalez-Lima, F. (2011). Low-level light therapy of eye and brain, Eye and Brain, 3, 49-67

Shining Universe Energy Books (2015). Brain-51 Powerful Ways to Improve Brain Power, Enhance Memory, Intelligence and Concentration. Published by Create Space Independent Publishing Platform

Simons, D. (2013). In 'Test Your Brain'. National Geographic, National Geographic Television

Sommer, A. P., Pinheiso, A. L., Mester, A. R., Franke, R. P., \& Whelan, H. T. (2001). Bio-stimulatory windows in low-intensity laser activation: lasers, scanners and NASA's light emitting diode array system. J Clin Laser Med Surg, 19, 29-33.

https://doi.org/10.1089/104454701750066910

Spinelli, S. et al. (2009). Early Life Stress Inducing Long-Term Morphologic Changes in Primate Brain. Archives of General Psychiatry, 66(6), 658-665

https://doi.org/10.1001/archgenpsychiatry.2009.52 


\section{Macrothink}

Business and Economic Research ISSN 2162-4860 2017, Vol. 7, No. 2

Strayer, D. (2013). In 'Test Your Brain'. National Geographic, National Geographic Television

Suomi, S. J. (1997). Early Determinants of Behaviour: Evidence from Primate Studies. British Medical Bulletin, 53(1), 170-184.

https://doi.org/10.1093/oxfordjournals.bmb.a011598

The Atlantic. (2017). Social Connection Makes a Better Brain. [Online] Available: http:// www.theatlantic.com/health/archive/2013/10/social-connection-makes-a-better-brain/280934/ (March 28, 2017)

Wikepedia. (2017). 'Ghost in the Shell'. Film released 2017. [Online] Available: http:// www.en.m.wikepedia.org (April 14, 2017)

Wong-Riley, M. T., Liang, H. L., Eells, J. T., Chance, B., Henry, M. M., Buchmann, E., Kane, M., \& Whelan, H. T. (2005). Photo-biomodulation directly benefits primary neurons' functionality inactivated by toxins: role of cytochrome C oxidose. J Biol Chem, 280, 4761-4771. https://doi.org/10.1074/jbc.M409650200

Thaler, R., \& Sunstein, C. (2008). Nudge-Improving Decisions about Health, Wealth and Happiness. Yale University Press

Quora. (2017). If the human brain were a computer it could perform 38 thousand trillion operations per second. [Online] Available: http://www.quora.com (April 14, 2017)

\section{Copyright Disclaimer}

Copyright for this article is retained by the author(s), with first publication rights granted to the journal.

This is an open-access article distributed under the terms and conditions of the Creative license (http://creativecommons.org/licenses/by/3.0/).1). 